\title{
Clashing Values: A Longitudinal, Exploratory Study of Student Beliefs about General Education, Vocationalism, and Transfer of Learning ${ }^{1}$
}

\begin{abstract}
One challenge with general education is the often-clashing goal of vocationalism, or educating for the purpose a specific careers or professions. Through a series of longitudinal interviews spanning a group of 14 students' second and fourth semesters at a public, regional research university, the author examines the intersection of beliefs and values about general education, transfer of learning, and vocationalism, and how these beliefs and values change over time. Findings reveal that for many students, vocationalism creates a single-minded focus on students' career preparation and major coursework and invites disregard for the value of general education courses that do not appear to immediately relate to students' future careers. This devaluing is particularly clear in students' first year; as students enter their sophomore years, they grow to value learning in general. The article concludes with suggestions for university-level and course-specific curricular change to better address vocationalism, value, and the need to transfer learning within general education courses.
\end{abstract}

\section{KEYWORDS}

transfer of learning, student beliefs, general education, vocationalism, epistemologies

Scholars investigating questions of teaching and learning often ask, "Are students going to use this material beyond my course?" This concept, known broadly as "transfer of learning," refers to how effectively students adapt their prior knowledge to other public, civic, educational, and professional settings. Transfer is crucially important to general education (GE) goals, proponents of which use broad preparation to hone literate, criti$\mathrm{cal}$, and productive scholars and citizens (Broudy, 1977). Understanding transfer is particularly relevant after the publication of Academically Adrift, in which Arum and Roksa (2010) questioned if college students are learning at all. Likewise, employers, faculty, and researchers have bemoaned students' inability to transfer as characterized by Haskell's (2000) suggestion that the problem with transfer is an "antibiotic-resistant bacterium" and "no matter what we attack it with, it just won't go away" (xiv).

How well students are able to transfer knowledge beyond GE courses is imperative to upholding the principles and long-term viability of higher education. Part of the chal- 
lenge with transfer is the often-clashing goal of vocationalism, students' single-minded focus on career preparation that invites disregard for courses that do not appear relevant to future careers. Because little has been written on the relationship of transfer of learning and vocationalism in GE, this article seeks to begin to fill this gap. Through a series of longitudinal interviews spanning a group of students' second and fourth semesters at a public, regional research university, the author examines how GE beliefs and values, transfer, and vocationalism intersect and change over time. Additionally, university-wide and course-specific suggestions are presented to better address vocationalism and emphasize transfer within GE courses.

\section{BACKGROUND AND SIGNIFICANCE}

\section{Transfer of learning}

Transfer is students' ability to apply and adapt knowledge and skills, whole or in part, in a wide variety of settings beyond their original learning contexts. The National Research Council (1999) suggests that "transfer" and "learning" are synonymous terms, and that without transfer, there is no learning (p. 61). Despite the NRC's emphasis on transfer, researchers have repeatedly noted that transfer is more likely to fail than to succeed. These failures include the challenge of building connections across courses and students' inability to generalize knowledge and adapt it beyond specific courses (McKeough, Lupart, \& Marini, 1995); the difficulty of student perceptions and value (Bergmann \& Zepernick, 2007; Driscoll, 2012); the need for a transfer-focused mindset (Haskell, 2000; Perkins, et. al., 2000) and the lack of opportunities to reinforce learning in the curriculum (Haskell, 2000). Successful transfer reflects 11 key components, which include the acquisition of a broad knowledge base, a substantial knowledge of the area to be transferred, systems that support transfer, motivation or a "spirit of transfer," and a clear understanding of transfer and how it works (Haskell, 2000, p. xv).

While some scholars have applied transfer principles to higher education more broadly (Benander \& Lightner, 2005; Billing, 2007; Halpern \& Hakel, 2003), these studies are few and far between. However, a rich disciplinary tradition of transfer research on specific GE courses exists, especially in writing studies (Wardle, 2007; Beaufort, 2007), mathematics (Evans, 1999), and language studies (James, 2009). In one such study, Driscoll (2012) identifies four types of student beliefs regarding writing transfer and the role of vocationalism in those beliefs. Likewise, Wells (2011), also studying writing, recognizes that beliefs and self-efficacy impacted her participants' ability to successfully transfer literacy skills from high school to college.

The above studies suggest that for successful transfer, students must inhabit the "spirit of transfer" (Haskell, 2000). In other words, they must demonstrate a willingness to abstract knowledge and to build connections. Haskell laments the lack of research into learner attitudes about transfer and suggests that transfer is as much about "a learner's state of being" as it is about specific skills applied (p. 115). The "spirit of transfer" is of critical importance for the design of this study and encourages us to examine students' beliefs and motivations as a way to study transfer.

\section{Values, beliefs, and personal epistemology}

Aligning closely with Haskell's (2000) spirit of transfer, research has also demonstrated that student beliefs, values, and epistemologies impact transfer (Beiriter, 1995; 
Driscoll \& Wells, 2011). Student behaviors, such as performance, persistence, and choice making, are directly related to the value students place upon a particular task or learning situation (Eccles, 2005). Beliefs, values, and epistemologies are related concepts, but each is distinct. Beliefs are the opinions and perspectives that students hold about their education, values are beliefs that assign worth, and epistemologies are particular beliefs about learning/knowing/doing (Bell, Halligan, \& Ellis, 2006). This section describes previous research concerning the impact of beliefs, values, and epistemologies on GE outcomes to establish their importance for the current study.

In 1968, Becker, Geer, and Hughes published Making the Grade, a yearlong study of undergraduate students' beliefs and behavior. In this groundbreaking work, they concluded that students respond to university-wide curriculum in unexpected ways. Student responses often result from beliefs that faculty and administrators do not foresee or understand. They discovered that students make decisions and interact with faculty almost exclusively on a "grade point average perspective" without much regard toward learning (p. 80). Twenty-four years later, Twombly (1992) suggested that most faculty and administrators don't see student beliefs as "valid sources" of information about learning (p. 243). Furthermore, Pascarella and Terenizini's (2005) groundbreaking How College Affects Students does not discuss general education specifically, although they do cover areas within the general education curriculum (verbal, quantitative, and subject matter competence) as well as attitudes and values, intellectual growth, psychosocial change, cognitive skills, and morals (pg. 573-574). While student beliefs and values have had some attention from the literature since that time, we still are a long way from understandingand effectively leveraging - beliefs and values in GE.

More broadly, research on epistemology has examined how constructions of knowledge positively or negatively influence students' educational experiences and performance. Hofer's (2000) "personal epistemology" refers to the beliefs about knowledge and knowing that substantially impact student learning (p. 85). In sum, student beliefs and values about knowing and learning profoundly shape their learning experiences and outcomes, marking them as worthy of further study.

Johnston et al. (1991) investigated the role of student beliefs about GE and found that GE experienced substantial revision in the latter part of the $20^{\text {th }}$ century on "the supply side" or through program design and faculty expertise building. However few revisions of curricula addressed the "demand side" or the "understandings, concerns, and attitudes that students bring to GE coursework" (p. 181). The authors argue that students need a better "meta-education" concerning GE; that is, students need to better understand what GE is, why it is required, and what they can gain from it. Johnston and his colleagues demonstrate that this meta-education is wholly lacking from many GE curricula; without it, GE curricula risk failure. These authors' arguments about GE and meta-education are closely aligned with discussions of the role of values or epistemological qualities and the spirit of transfer. Drawing parallels between the two, this meta-education is critical to ensure that students value and transfer their learning, a point that will be returned to at the end of this article.

\section{Vocationalism and its impact on GE}

Any discussion of student beliefs, values, and epistemologies must also account for vocationalism, a critical driving force within higher education, especially in relationship 
to GE goals (Harris, 2006). Gaff and Davis (1981) found that while students valued their GE coursework, particularly work that provided critical thinking, communication, and interpersonal skills, they were also critical when it was not focused on explicit career preparation. Thirty years later, this same tension is echoed throughout GE literature (Paul, 2005; Smith, 2000).

Limited research has examined how beliefs and values, including vocational values, have impacted students in GE. Twombly's (1992) study focused on student beliefs about professional or vocational education and GE by conducting focus groups of freshman and sophomore students within professional and non-professional majors. She discovered that students identify four purposes for GE: educational (well-rounded, knowledge of culture, etc.), instrumental (building confidence, discipline), personal (better understanding of one's self), and negative (obstacle). Twombly uncovered two influences on student beliefs of GE: 1) perceptions of usefulness in future profession and life and 2) people in their lives, such as siblings, parents, and faculty (p. 259). Likewise, Anderson et. al. (2007) examined attitude change in a GE course and argued that many GE curricula neither address nor measure students' attitude changes. While these two studies have examined values and beliefs concerning GE, only one (Anderson et. al, 2007) examines the current generation of college students in a longitudinal study. Furthermore, both studies call for more explicit measurement of GE attitudes and beliefs, a call that the present study attempts to fill. It is clear that much more research, including research from a longitudinal perspective, is needed to better understand beliefs and values, including vocationalism, within GE.

\section{RESEARCH QUESTIONS}

While research has investigated the role of transfer of learning, student beliefs and values, and vocationalism within GE in separate ways, prior studies have neither examined their intersections nor investigated their changes longitudinally. Twombly (1992), Pascarella and Terenzini (2005), and Anderson et al. (2007) provide clear suggestions for examining students' attitudes and beliefs over time. Driscoll and Wells (2012) suggest that internal student characteristics are critically important to understanding transfer of learning - reinforcing the importance of studying attitudes and beliefs about transfer and GE. Researchers studying transfer also frequently employ a longitudinal, qualitative approach (Beaufort, 2007; Wardle, 2007).

The overarching question this study attempts to address is How are transfer oflearning and beliefs about vocationalism related to GE goals? This question is answered through the following two sets of questions:

1. What do undergraduate students believe are the purposes and goals of GE? Is GE valued? How do these beliefs change in students' first two years of higher education?

2. Do students inhabit the "spirit of transfer" concerning their GE work? Does this perspective change in students' first two years of higher education?

\section{METHODS}

\section{Study context and GE curriculum}

Oakland University (OU) is located in the northwest suburbs of Detroit, Michigan. In fall 2011, the first year of data collection, OU had a total student enrollment of 19,379, 
including 15,838 undergraduate students. As a public, regional research university, OU offers a strong emphasis in undergraduate education. OU's campus-wide GE curriculum seeks to balance broad knowledge with "analytical and evaluative tools needed to lead productive and fulfilling lives of leadership and service." ${ }^{2}$ The GE curriculum, which comprises approximately $33 \%$ of most degree programs, includes "foundations" in formal reasoning and writing and "explorations" in the arts, foreign languages/cultures, global perspectives, US diversity, literature, natural science, technology, social science, and western civilizations. It also includes "writing intensives" in which at least $20 \%$ of the final grade is based on writing, "integrations" where students apply knowledge in a wide variety of contexts, and an in-major capstone experience. All courses are encouraged to promote effective communication, critical thinking, social awareness, and/or information literacy.

Participants were recruited from GE first-year writing courses in the fall 2011 semester, and follow-up interviews were conducted in 2012. Over 95\% of FTIAC (first time in any college) students place into one of three first-year writing courses based on ACT scores, which were used for recruitment. The goal in recruiting from these courses was to gain a representative sample of FTIAC students.

\section{Participants}

Participants were recruited via email from a sample of $25 \mathrm{GE}$ composition courses in the fall 2011 semester. One student was selected randomly from each class; initially, $70 \%$ of contacted students (20 students) agreed to participate. Two students' schedules would not permit time for interviews, which left 18 participants for year 1 (Y1) of the study. Participants were interviewed at the start of their second semester and interviewed again at the start of their fourth semester (Y2). Four students were not able to be interviewed during their fourth semester: three due to no longer being enrolled and one due to loss of life. Because this study focused on a longitudinal analysis as students completed their GE courses, the four students who did not complete Y2 interviews were omitted from the analysis.

The fourteen remaining participants ( 5 males, 9 females) came from diverse majors, including social science (2), education (2), science (2), health sciences/nursing (4), and undecided (4). ${ }^{3}$ Participants represented a range of ethnicities: Hispanic (1), $2^{\text {nd }}$ generation Finnish (1), generation 1.5 Russian (1), African American (1), and Caucasian (11). Major and ethnicity patterns are representative of the broader student body at OU.

\section{Interviews}

Semi-structured interviews included questions and prompts about GE, learning transfer, and writing experiences. Interviews lasted 45 to 60 minutes, and students were compensated \$20. Follow-up interviews during Y2 asked students the same questions for comparisons over time; in Y2, students also responded to specific questions based on their Y1 interview. Questions about GE included "Are you familiar with the term GE or Gen Ed?" "What do you believe is the purpose of GE?” "Do you value GE (If so, why so? If not, why not)?" and "Who makes decisions about GE?" Students were also asked questions about transfer including the following: "Teachers see what they call the 'box under the bed.' This is when students are asked to recall information that have learned in previous courses; they find that students, metaphorically, take knowledge and put it in a box under the bed rather than actively working to retain it. What are your thoughts on 
the accuracy and relevance of this metaphor to your own learning?" "How do you decide what knowledge in your courses is most important?" "Do you work to actively retain and use knowledge beyond your courses? If so, how? If not, why not?" "Can you give an example of a place where you used knowledge from X course in another place?”

\section{Analysis}

A multi-level coding strategy was used to examine the interview data (Saldaña, 2009). First, beliefs about GE and transfer were open coded to identify themes and patterns, including examining positive/negative/neutral beliefs and tracking how students answered the same questions during Y1 versus Y2. After a second round of open coding, codes were further refined; a final round of coding is represented in the results presented here. Individual student changes were qualitatively and quantitatively examined. However, due to the small sample, no inferential statistics were calculated. Four students with diverse educational and ethnic backgrounds and representative views from the larger sample were selected as illustrative cases.

\section{Limitations}

One limitation is the small number of participants at a single study site; the study sample was further reduced by the loss of four participants during Y2. Its also unclear if some self-selection bias is present in the study sample because students were recruited from GE composition courses, and $70 \%$ of the sample responded; it is unknown how students who were recruited differ from those who were not. Additionally, because this study relies on self-reported interview data, results are limited to what students report rather than a direct measure of student behavior. Finally, information about socioeconomic status was not collected from participants.

\section{RESULTS}

First, the overall results for all students in the study are presented with each research question. Following the broad discussion, four students-Derek, Nora, Julie, and Aliceare described in more detail to provide greater depth and illustration of the patterns that emerged. To better understand these students and their backgrounds, epistemological perspectives concerning learning and demographic information is first presented here.

Two of the case study students demonstrated a personal epistemology that strongly valued learning and a belief that all learning is useful. Derek is a traditional-aged Caucasian student majoring in secondary education with an emphasis in history. Many of Derek's epistemological values concerning education were instilled through his parents, who teach in the secondary school system. Coming from a competitive high school with strong parental support, Derek entered college "quite ready." Julie is traditional-aged, generation 1.5 immigrant from Russia whose major was undecided during both years of the study. Although Julie went to a "good high school," the high school placed Julie into a non-honors track, which gave her less preparation than some of her peers. Julie's personal epistemology toward learning is quite positive: she values learning and invested effort in her studies.

The last two students have less positive personal epistemologies about learning. Alice is a traditional-aged Caucasian majoring in psychology. Alice came from an "O.K." school and took mostly "basic courses" but had the opportunity to take an Advanced Placement 
psychology class. Most of Alice's educational struggles come from being diagnosed with dyslexia, which impacted her math and literacy skills. Despite her challenges, Alice understood the school system and "the game" and was very focused in her psychology courses, demonstrating a high amount of value towards psychology — at the expense of anything else. Nora is a traditional-aged Hispanic student studying pharmacy. She expressed frustration with her high school courses and felt that they did not prepare her for college. Like Alice, Nora is focused on her future career as a pharmacist. Unlike the other three students, however, Nora demonstrates a strong external locus of control (Weiner, 2010), indicating that her success as a student depends more on her outside influences (like faculty, peers) than on her own abilities or responsibility.

\section{Research question set 1: What do undergraduate students believe are the purposes and goals of GE? Is GE valued? How do these beliefs change in students' first two years of higher education?}

Interviews with all four participants revealed values that were diverse, complex, and sometimes contradictory. Students made 80 distinct statements in their Y1 and Y2 interviews about GE. Many expressed both positive and negative beliefs about the role of GE in their studies and in their lives. Three major themes emerged concerning student beliefs about the purpose of GE: A) GE allows me to become a well-rounded person with an educationally diverse background, B) GE allows me to explore possible majors and/ or connect knowledge to my major, and C) GE is a money-making strategy on the part of the university and wastes my time. Statements A and B can be framed negatively or positively; $\mathrm{C}$ was only found in relationship to negative beliefs.

\section{Positive beliefs}

Table 1 provides a list of positive beliefs and how they changed over time based on the number of students who identified with each belief each year (some beliefs are expanded from the three statements listed above). In Y2, more students displayed positive beliefs concerning the GE curriculum than in Y1; the most prominent Y2 belief was that GE allowed them to become a well-rounded individual. It is important to note that all

Table 1. Positive Beliefs about GE

\begin{tabular}{|c|c|c|c|}
\hline & $\begin{array}{l}\text { YEAR } \\
\text { ONE }\end{array}$ & $\begin{array}{l}\text { YEAR } \\
\text { TWO }\end{array}$ & $\begin{array}{l}\text { CHANGE } \\
\text { OVER TIME }\end{array}$ \\
\hline $\begin{array}{l}\text { - GE offers me an opportunity to choose interesting courses I } \\
\text { would not otherwise take. }\end{array}$ & 1 & 2 & +1 \\
\hline $\begin{array}{l}\text { - GE allows me to become a well-rounded person with an } \\
\text { educationally diverse background. }\end{array}$ & 5 & 9 & +4 \\
\hline $\begin{array}{l}\text { - GE helps prepare me for my major coursework or build } \\
\text { connections to my major/field. }\end{array}$ & 2 & 5 & +3 \\
\hline $\begin{array}{l}\text { - GE is useful to undecided students because they gain exposure to } \\
\text { a wide variety of disciplines. }\end{array}$ & 5 & 1 & -4 \\
\hline $\begin{array}{l}\text { - GE courses are easier, giving you a "break" from difficult major } \\
\text { courses. }\end{array}$ & 4 & 2 & -2 \\
\hline
\end{tabular}


interviewed students who held positive beliefs about GE also expressed a high value of learning; learning was one of their primary reasons for being at the university.

Julie expressed largely positive views about GE in both Y1 and Y2. Unlike many students interviewed, Julie not only understands the basic principles of GE but also how those principles are meant to interact with her vocation. In her first year, when asked why the university requires GE courses, she replied,

I really value that I can be knowledgeable on many things and be the smart one of the bunch.... I think the university [offers GE courses] because when you go into a particular field... you're going to need other knowledge too. So all the knowledge kind of comes together and you can use it for your job. It's also good to be knowledgeable about the world.

Because Julie holds a high value in learning, she sees GE as a positive experience in her career and beyond. Furthermore, as an undeclared major, Julie finds GE particularly helpful as she explores potential career paths. Her Y2 interview yielded the following:

Julie: I think [GE is] perfect. Because you can't really know what you're interested in until you've tried everything. I think that's a huge thing.

Researcher: What do you think the university's purpose is in requiring GE courses?

Julie: Maybe to raise awareness to every department, because I think like Physical Therapy's a huge one, or Nursing, but those are like the general, "I want to be a nurse! I want to be a teacher!" That kind of thing, whereas when you have Gen Ed, you're like, "Oh, I'm kind of interested in this now" because I was exposed to it.

The only negative thing that Julie had to say about GE in Y1 and Y2 was cost: "I wish it didn't cost so much ... I just hate that I have to pay so much for it." This is an issue that many students, even those with high appreciation for GE, discussed.

\section{Negative beliefs}

Five categories of negative beliefs concerning GE also surfaced (Table 2). Clearly, GE coursework invokes emotion in some students: three students expressed anger concerning GE requirements, even to the point of banging their fists on the table, swearing, raising their voices, or using obscene language. Despite emotional reactions, fewer students during Y2 believed that GE wasted their time, although they continued to believe that GE was in existence so that the university could make money. During Y1, six students understood but disagreed with the overall purpose of GE, but this was reduced to only two students during Y2. Students did, however, have more difficulty seeing a connection between GE and their major in Y2, an issue related to vocationalism.

Many of the students' statements demonstrate that they value their majors - and future vocations - substantially more than GE courses. Alice is very negative about GE:

I told you last time, ${ }^{4}$ I hate them. I still hate them. Gen Eds can be fun but you know I'm not here for fun.... My time here would be so much shorter and so much cheaper if I didn't have to take Gen Eds. And for someone 
Table 2. Negative Beliefs about Goals of GE

YEAR ONE YEARTWO CHANGE

\begin{tabular}{llll}
\hline - Talking about GE makes me angry/upset. & 1 & 2 & +1 \\
\hline - GE is a waste of my time. & 6 & 4 & -2 \\
\hline $\begin{array}{l}\text { - I see no clear connection between GE coursework and my } \\
\text { major/future career. }\end{array}$ & 2 & 5 & +3 \\
\hline - GE exists so that the university can make money. & 6 & 7 & +1 \\
\hline $\begin{array}{l}\text { - While I understand the purpose of GE, I disagree with that } \\
\text { purpose. }\end{array}$ & 6 & 2 & -4 \\
\hline
\end{tabular}

like me who I came into college knowing what I wanted to do, I have always known what I wanted to do so for me it's just like extra fluff. It's just me throwing away money. Sure the tools I learned will help me in some way, but do I really need an Art History class? Probably not. Will it give me a better appreciation of art? For sure. But is that really going to help me psychoanalyze someone someday? No ... that was like a thousand dollars that I just wasted.

In other parts of her interview, Alice also expresses concern that GE courses are "preventing me from going out and helping people faster." In this case, Alice is demonstrating a vocational view of GE, and sees GE more of a hurdle to be overcome rather than a learning opportunity.

\section{Conflicted beliefs}

Some students' sentiments about GE were conflicted and filled with uncertainty. In both years, about half of the students in the sample demonstrated conflicting beliefs (six in year one, seven in year two, for a change of +1 ). Conflicted beliefs most often involved the relationship between developing an understanding or broad knowledge of the world versus spending time/money to gain a degree, although some students (such as Derek, described below) demonstrated more nuanced understandings.

Nora represented a great example of a student expressing conflicted values about GE. In Y1, she says,

\section{I don't want to say that [GE courses] are useless because I don't want to} take human anatomy, biology, chemistry, and the anatomy lab and all of that in one semester. But obviously with those 40 extra credits ... it will make my graduation a lot further away. But they kind of balance out my semesters.

Part of Nora's emphasis on balance comes her substantial struggles in her major prerequisite courses; Nora's struggle with her major courses influences her relationship with GE.

Derek has a very different set of conflicted issues with GE. Derek describes GE as an "attempt by a school to give every student a broad area of basic knowledge ... a bunch of information that covers a wide range for you to draw on to do your major courses." Yet in Y1, Derek does not believe GE is accomplishing its goals: 
It's because of the lack of cohesion between it all. It's because when you walk into the Gen Ed class, it's either the professor's attitude or the student's attitude or the way its taught that you do just put it in a box and never bring it out again.... I find [Gen Eds], for the most part, dull. It feels more like [faculty] are approaching it just the way students are, "Here's another throwaway class, just get it done, get it out of the way" when it really should be looked at as "here's a basis of knowledge for everybody to have.

Derek's comments about attitudes of students and faculty get to the heart of this study in that Derek is aware of the conflicted status of GE and that conflict is impacting his ability to get the most from his courses. To solve the problem, Derek makes suggestions not all that dissimilar from those that will be discussed in the article's conclusion. He says,

It needs to be preached to the people, like when you're incoming as a freshman... they need to know what it's there for. It's not just "here's some classes that you have to soak up some of your money, to soak up some of your time, to give a couple of our teachers a job to do." They need to approach it and learn that it is, literally, just a triangle [of learning], broad to specific.

\section{Research question set 2: Do students inhabit the "spirit of transfer" concerning their GE work? Does this perspective change in students' first two years of higher education?}

Although I asked students about their beliefs concerning transfer in an earlier and separate part of the interview, students often articulated their experiences with specific GE coursework when discussing transfer. Table 3 describes students' responses to questions concerning transfer of their university coursework. During Y1, 10 of the 14 students expressed a vocational view of transfer - that is, transfer of learning was based on whether they saw direct and clear connections between the course and their future careers. In Y2, only five students still expressed this view, a finding that aligns with their growing understanding about non-vocational values of education demonstrated above.

While some transfer beliefs are course specific_-based on the professor's emphasis or cumulative courses-more are based on the personal epistemologies and beliefs of individual students. Of particular concern is the last belief in Table 3, where students report purposely working to forget knowledge from a course after the course ends; in all nine instances, this was discussed in relationship to a GE course.

When students discussed transfer, they often mentioned specific GE classes that they felt would not be useful to them in the future. Alice expresses a very typical view of transfer tied to vocationalism:

For me if it's going to be beneficial future career [I keep it]. So anything I learn in a psychology class I try to remember. I try to store it away. Especially when people find out that your major is psychology... I have friends that come up to me who are in PSY100 and they're like "help me study" and I'm like "I haven't taken this class in a year now but I got to remember things to tutor them."... So like something like math, unless its statistics for psychology, I'm not going to remember after the class. 
Table 3. Beliefs about the Transfer of Learning

YEAR ONE YEARTWO CHANGE

\begin{tabular}{|c|c|c|c|}
\hline $\begin{array}{l}\text { - Transfer is based on the professor's emphasis and/or } \\
\text { personality (external locus of control). }\end{array}$ & 8 & 6 & -2 \\
\hline - Transfer is challenging because it is hard to recall information. & 3 & 4 & +1 \\
\hline $\begin{array}{l}\text { - Transfer is more likely if I am seeing material directly } \\
\text { connect to other courses I am taking. }\end{array}$ & 4 & 5 & +1 \\
\hline $\begin{array}{l}\text { - Transfer is more likely if I am seeing material directly } \\
\text { connecting to my major or future career. }\end{array}$ & 10 & 5 & -5 \\
\hline $\begin{array}{l}\text { - Transfer is more likely if course is and/or if it will appear on } \\
\text { the final exam. }\end{array}$ & 1 & 3 & +2 \\
\hline $\begin{array}{l}\text { - Transfer is more likely if I find the subject interesting and } \\
\text { relatable to my personal life. }\end{array}$ & 4 & 5 & +1 \\
\hline $\begin{array}{l}\text { - Everything I learn has value so I attempt to transfer all } \\
\text { content from my courses. }\end{array}$ & 0 & 3 & +3 \\
\hline $\begin{array}{l}\text { - I have purposely attempted to forget knowledge after a } \\
\text { course ends. }\end{array}$ & 4 & 5 & +1 \\
\hline
\end{tabular}

Nora bases transfer not on whether it connects to her career but instead on how "good" her teacher is (tying back to her external locus of control):

I think that reflects to "I have this great teacher in college." It reflects like if you remember the teacher, you remember the class. You remember if you had a good time in that class. If you are going to have a bad teacher, you are going to remember the bad teacher and... how much you didn't want to be with that teacher and you don't remember the class.

Julie, who expressed a positive personal epistemology concerning learning, works hard to remember everything using a particular study technique that involves repetition and daily review of her material:

It's like $60 \%$ of the information we learned, we tend to forget. But I really try hard not do to that and that goes back to my way of studying. I really try to review a little bit of each course and just look back at the stuff we went over the day and previously, so it sticks.

Despite her emphasis on learning and its value, Julie too demonstrated a vocational view of transfer concerning her physics class:

Physics is not my strongest subject to say the least... I have actually talked to several registered architects and they say that physics isn't required... that's more the job of an engineer, an architectural engineer. So I'm just like, eww, under the bed. ${ }^{5}$

These students' comments also led to discipline-specific findings about GE and transfer. Students indicated challenges in connecting and transferring particular kinds of GE courses, including math ( 8 students), science ( 5 students), history ( 5 students), and 
writing ( 2 students). In all cases, students reported having difficulty in connecting knowledge between diverse courses and their major (e.g., science courses for a writing major).

In the above interview segments, vocationalism appears to be a determining factor for students' reports of value and transfer of GE coursework. For half of the students in the study, a lack of a perceived direct connection to their career led students to report unsuccessful transfer because the "spirit of transfer" is simply not embodied. The results also suggest a connection among transfer of learning, GE, and vocationalism. When students fail to see a direct connection to their majors or future careers, they devalue GE courses and indicate they do not take effort to retain and transfer knowledge from those courses. This relationship appears particularly strong in students' first year in college but is still present in their second year.

\section{DISCUSSION}

This study has a number of relevant findings that can assist us in understanding student beliefs and values concerning GE, vocationalism, and transfer. These findings, while coming from a small group of students, can still provide us with insights and questions for further study and can reinforce previous findings. In this section, the immediate findings will first be discussed and then a set of pedagogical suggestions arising from this study and previous findings will be presented.

First, findings suggest that while the majority of students can articulate widely agreedupon core goals and values of GE courses, they do not necessarily agree with those goals because of their vocational attitudes and/or concerns for paying for college (as Alice and Nora reflected). Some participants, especially in their first year of coursework, see GE courses as a waste of time and money because these courses appear disconnected from their majors and careers and because they have not been taught otherwise. For these students, preparation for a career is the goal of their enrollment in college, and anything that they perceive as not immediately aligning with their goal is viewed negatively. Grubb and Lazerson (2005) suggest that traditional values and goals of GE are frequently questioned by vocationally-based students. These findings also support Twombly's (1992) study that found that the "usefulness" of GE was based, in part, on students' perceptions of how content would be applicable in their professions. In the present study, students rarely saw the connection between GE coursework, majors, and vocations. The lack of such connections, made on the part of the student or faculty, led to challenges with transfer, where students report purposely throwing away knowledge that could otherwise benefit the student intellectually, civically, or professionally. Haskell's (2000) work applies here: if students fail to see value in GE courses, they fail to gain the "spirit of transfer" that is so critical for success.

The study results further suggest that patterns of belief concerning GE and transfer change over time, including some shifts away from the near-obsessive vocationalism in Y1 to more positive beliefs concerning GE in creating well-rounded individuals in Y2. At the same time, however, many students in the study in both years still demonstrate a lack of value for GE. Even though a number of students in the study expressed negative views of transfer from GE, a second group of students were positive about the overall impact and value of their GE courses. For these students, GE offered the chances for exposure to new ideas, to connect various subjects, and to find a major (for undecided students). 
The difference between the various students in the study appears to be related, in part, by their personal epistemologies (Hofer, 2000) toward learning.

The present findings corroborate Johnston and his colleagues' (1991) concept of the "demand side" of education is further validated with the data presented in this study, where beliefs, values, and epistemologies that students bring to GE are critical to self-reported transfer. The majority of students report that they retain and transfer information that is either directly connected to their majors and careers or that they find "interesting" or relatable to their lives. ${ }^{6}$ While these trends decrease in Y2, since many students take the majority of their GE coursework in their first two years, these trends raise potential concerns about the transferability and student devaluing of GE courses.

Derek's interview comments are also worth considering. While Derek understands GE's overall goals, he sees the GE courses he has taken as failures. He suggests this is due to attitudes of students and faculty, as well as what Johnston and his colleagues (1981) call "metaeducation" about GE coursework. This finding suggests that in order to address the challenges raised by Derek, then, we need to pay more attention to how students experience and understand the GE curriculum.

\section{Suggestions for classroom and curricular change in higher education}

With the substantial rise in vocationalism in the $20^{\text {th }}$ century (Grubb \& Lazerson, 2005; Harris, 2006), scholars document an increasing tension between vocationally driven undergraduates and GE coursework designed to prepare students for broad purposes. Harris (2006) describes how vocationalism and consumerist mindsets prompts students to be "in the position of solely determining what is valued in the academic experience, without the theoretical and pedagogical underpinnings necessary for making the proper decisions" (p. 192). He argues that students see education as a "product to be purchased" (p. 192) where students select courses, programs, and majors based on their potential economic gain rather than educational goals. Harris further argues that while one of GE's main aims is to produce good citizens, students often overlook this goal due to their consumerist and vocational values. Likewise, Grubb and Lazerson (2005) demonstrate that traditional GE purposes — civic, intellectual, and moral — have been under attack by students who view the purpose of higher education as vocational. They conclude that curricula must be designed to address vocational as well as GE goals. Ryan (2003) argues that that vocationalism and liberal educational values can be merged through new initiatives like service learning-but not all programs are doing this successfully.

When coupled with the above literature concerning transfer, vocationalism, and GE, present study findings suggest the need for envisioning and articulating clearer connections between vocationally-driven students and GE to empower students not only to be well-rounded but also to apply knowledge from GE courses to public, professional, and civic lives. Johnston, et al. (1991) argues that not only do colleges and universities need to understand the perceptions of GE students bring with them, but also they need to effectively address, shift, and build more positive perceptions of GE (p. 195). Toward that end, the following are three suggestions to help build connections while facilitating transfer.

First, we must educate students early and often about the overall purpose and goals of GEproviding a "metaeducation" - to facilitate positive values and attitudes. Grubb and Lazerson (2005) suggest that students need to be educated about GE from their very first experi- 
ences at the university, including during admissions, orientation, and academic advising, a suggestion supported by this study. Students needed more direct education early on about the purpose of GE as well as a better understanding of precisely how broad skills like critical thinking and literacy can aid them in life. For this education to be effective, it must be a university-wide effort. It is through these early interactions that students can understand, before they even take their first college class, why GE coursework is part of their degree. Once they arrive in our classrooms, especially within in their first semester, we need to provide students with opportunities to discuss GE, to understand its purpose, and to demonstrate how GE is useful in a wide variety of careers and contexts.

Second, we must create programs that scaffold and encourage transfer of learning so students can see how their GE connects to their majors and careers. Creating transferrable GE programs begins with the identification of key skills within the curriculum that transfer between courses. Harris (2006) identifies critical thinking, ethics, argumentation, and writing as such skills; additionally, scientific literacy, numerical literacy, interpersonal skills, and metacognitive skills can be added to this list. We need to develop ways of holding students accountable for learning in prior courses and to reinforce that learning in subsequent coursework. We also need to give faculty opportunities for cross-talk and collaboration among the many different courses within the GE and disciplinary curriculum.

Benander and Lightner (2005) describe experiences teaching transfer-focused courses within their GE curriculum. They argue that we must make transfer an explicit expectation, advise students to take courses in sequential order, provide them rationales for such sequencing, and model transfer in courses by inviting guest speakers and carefully designing assignments. Adding to their advice, this study suggests that students must be provided with opportunities to see how their coursework connects to and provides skills for their majors and future professions. Students can engage in homework or writing inquiry projects where they build bridges between their courses, learn about how a particular GE skill applies in their field, or conduct interviews with professionals about GE skills.

Encourage metacognitive awareness about GE and engagement in transfer-focused thinking. The specific knowledge that students gain in courses is only part of a successful learning environment. Another part includes the mindsets and dispositions students hold toward learning. This suggestion aligns with metacognition, otherwise known as thinking about thinking or learning about learning, which serves as a way for students to understand themselves as learners and facilitate transfer (Nodoushan, 2008). A simple way to encourage metacognition is to ask students to reflect upon where they are in their learning process using questions: "What do I know about X already?" "What do I need to know about X?" "What resources do I need to gain X information?" "How does this connect to X?" "How can I take X with me beyond this assignment/course?"

\section{CONCLUSION}

Harris (2006) argues that we need to recognize that students' emphasis on consumerism and vocationalism are permanent features of the academic landscape of higher education. As such, we need to work to develop creative, critical, and innovative GE curriculum that uses existing vocational attitudes to build value for students and to foster transfer while also recognizing students like Julie and Derek who want to learn for learning's sake. This article examined the relationship of a group of students' vocational values and beliefs about GE in the context of transfer. While it has provided suggestions for building meta- 
cognitive awareness about GE and more connected GE courses, it also raises a number of questions worthy of future study on diverse populations. These questions include the following: How are values about GE related to course performance, persistence, and retention? Are students able to transfer knowledge between GE coursework and major coursework? If so, what allows them to do so? If not, what prevents them from doing so? What other pedagogical interventions can we develop to address issues of value in GE? Through answers to these and other questions, we can more readily address the challenge of educating students within a vocationally-driven educational setting.

Dana Lynn Driscoll is Assistant Professor of Writing and Rhetoric and Faculty Fellow for the Center in Excellence in Teaching and Learning at Oakland University (USA).

\section{NOTES}

1. Special thanks to Wallis Anderson, Gwen Gorzelsky, Ed Jones, Sherry Wynn-Perdue, and two anonymous reviewers for their comments on this manuscript. This research is supported in part by a grant from the Oakland University Research Committee.

2. Taken from the university GE website (http://www.oakland.edu/gened).

3. These are student majors for the first year; in their second year, two undecided students chose majors in health science and education while two remained undecided.

4. Alice is referring to the previous year's interview.

5. The "box under the bed" refers to the question asked about transfer of learning described in the methods section.

6. How accurate a student's knowledge of his/her future profession is a question raised by this finding. While few students in the study reported having family in similar professions, the majority demonstrated little understanding of their future career.

\section{REFERENCES}

Arum, R., \& Roksa, J. (2010). Academically adrift: Limited learning on college campuses. Chicago, IL: University of Chicago Press.

Beaufort, A. (2007). College writing and beyond: A new framework for university writing instruction. Logan, Utah: Utah State University Press.

Becker, H. S., Geer, B., \& Hughes, E. C. (1968). Making the grade: The academic side of college life. Hoboken, NJ: Wiley.

Bell, V., Halligan, P. W., \& Ellis, H. D. (2006). A cognitive neuroscience of belief. In P. W. Halligan \& M. Aylward (Eds.), The power of belief: Psychological influence on illness, disability, and medicine (pp. 3-20). Oxford: Oxford University Press.

Benander, R., \& Lightner, R. (2005). Promoting transfer of learning: Connecting general education courses. The Journal of General Education, 54(3), 199-208.

Bereiter, C. (1995). A dispositional view of transfer. In A. McKeough, J. Lupart, and A. Marinin (Eds.), Teaching for transfer: Fostering generalization in learning (pp. 21-34). Mahwah, NJ: Lawrence Erlbaum Associates.

Bergmann, L., \& Zepernick, J. (2007). Disciplinarity and transference: Students' perceptions of learning to write. WPA Journal, 31(1/2), 124-149. 
Billing, D. (2007). Teaching for transfer of core/key skills in higher education: Cognitive skills. Higher Education, 53(4), 483-516.

Broudy, H. S. (1977). Types of knowledge and purposes in education. In R. C. Anderson, R. J. Spiro, \& W. E. Montague (Eds.), Schooling and the aquisition of knowledge (pp. 1-17). Hillsdale, NJ: Erlbaum.

Driscoll, D. L. (2011). Connected, disconnected, or uncertain: Student attitudes about future writing contexts and perceptions of transfer from first-year writing to the disciplines. Across the Disciplines, 8(2).

Driscoll, D. L., \& Wells, J. (2012). Beyond knowledge and skills: Writing transfer and the role of student dispositions. Composition Forum, 26.

Eccles, J. (2005). Studying the development of learning and task motivation. Learning and Instruction, 15(2), 161-171.

Evans, J. (1999). Building bridges: Reflections on the problem of transfer of learning in mathematics. Educational Studies in Mathematics, 39(1/3), 23-44.

Gaff, J. G., \& Davis, M. L. (1981). Student views of general education. Liberal Education, 67(2), 112-123.

Grubb, W. N., \& Lazerson, M. (2005). Vocationalism in higher education: The triumph of the education gospel. The Journal of Higher Education, 76(1), 1-25.

Halpern, D. F., \& Hakel, M. D. (2003). Applying the science of learning to the university and beyond: Teaching for long-term retention and transfer. Change, 35(4), 36-41.

Harris, M. S. (2006). Out out, damned spot: General education in a market-driven institution. The Journal of General Education, 55(3), 186-200.

Haskell, R. E. (2000). Transfer of learning: Cognition and instruction. New York: Academic Press.

Hofer, B. K. (2000). Dimensionality and disciplinary differences in personal epistemology. Contemporary Educational Psychology, 25(4), 378-405.

James, M. A. (2010). An investigation of learning transfer in English-for-general-academicpurposes writing instruction. Journal of Second Language Writing, 19(4), 183-206.

Johnston, J. S., Reardon, R. C., Kramer, G. L., Lenz, J. G., Maduros, A. S., \& Sampson, J. P. (1991). The demand side of general education: Attending to student attitudes and understandings. The Journal of General Education, 40, 180-200.

McKeough, A., Lupart, J. L., \& Marini, A. (1995). Teaching for transfer: Fostering generalization in learning. Mawah, New Jersey: Lawrence Erlbaum.

National Research Council (1999). How people learn: Brain, mind, experience, and school. Washington D.C.: National Academy Press.

Nodoushan, M. A. S. (2008). The role of metacognition in the language teaching profession. Journal of Educational Psychology, 2(1), 1-10.

Paul, D. A. (2005). Higher education in competitive markets: Literature on organizational decline and turnaround. The Journal of General Education, 54(2), 106-138.

Pascarella, E. T., \& Terenzini, P. T. (2005). How college affects students: A third decade of research. San Francisco, CA: Josey-Bass. 
Perkins, D., Tishman, S., Ritchart, R., Donis, K., \& Andrade, A. (2000). Intelligence in the wild: A dispositional view of intellectual traits. Educational Psychology Review, 12(3), 269-293.

Ryan, P. (2003). Evaluating vocationalism. European Journal of Education, 38(2), 147-162.

Saldaña, J. (2009). The qualitative coding manual. Thousand Oaks, CA: Sage.

Salomon, G., \& Perkins, D. N. (1989). Rocky roads to transfer: Rethinking the mechanisms of a neglected phenomenon. Educational Psychologist, 24(2), 113-142.

Smith, C. W. (2000). Market values in American higher education: The pitfalls and promises. Lanham, MD: Rowman \& Littlefield.

Twombly, S. B. (1992). Student perspectives on general education in a research university: An exploratory study. The Journal of General Education, 41, 238-272.

Weiner, B. (2010). Attribution theory. In I. B. Weiner \& W. E. Craighead (Eds.), The Corsini encyclopedia of psychology (pp. 184-186). Hoboken, NJ: John Wiley \& Sons.

Wardle, E. (2007). Understanding "transfer" from FYC: Preliminary results of a longitudinal study. WPA Journal, 31(1/2), 124-149.

Wells, J. H. M. (2011). Millennials strike back: Students' reports of knowledge transfer from high school to college. (Unpublished doctoral dissertation). Indiana University of Pennsylvania, Indiana, PA. 